\title{
Electron-Gamma PAC: New Possibilities for NQI Studies
}

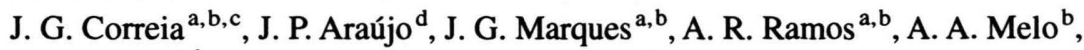 \\ J. C. Soares ${ }^{a, b}$, and the ISOLDE Collaboration ${ }^{c}$ \\ a ITN, Estrada Nacional 10, P-2686-953 Sacavém, Portugal \\ b CFN, Univ. Lisboa, Av. Prof. Gama Pinto 2, P-1649-003 Lisboa, Portugal \\ c EC/SC Division, CERN, CH-1211 Geneva, Switzerland \\ d IFIMUP, Univ. Porto, Rua do Campo Alegre 687, P-4150 Porto, Portugal \\ Reprint requests to J. G. C., Fax: 0041 (22) 767 8990, E-mail: guilherme.correia@ cern.ch
}

Z. Naturforsch. 55a, 3-14 (2000); received September 11, 1999

Presented at the XVth International Symposium on Nuclear Quadrupole Interactions, Leipzig, Germany, July 25-30, 1999.

\begin{abstract}
The application of hyperfine interaction techniques to problems in solid state physics has been steadily growing over the last decade with the use of radioactive ion beam facilities such as ISOLDE at CERN. New applications of the $e^{-}-\gamma$ Perturbed Angular Correlation (PAC) technique are underway at ISOLDE using probe nuclei with highly converted cascades. In this paper we present the motivation for extending PAC experiments to elements/isotopes not usable with the conventional $\gamma-\gamma$ PAC technique. Examples will be shown where the long-lived ${ }^{73} \mathrm{As} /{ }^{73} \mathrm{Ge}$, the short lived ${ }^{127} \mathrm{Ba} /{ }^{127} \mathrm{Cs}$ and the ${ }^{197 \mathrm{~m}} \mathrm{Hg} /$

${ }^{197} \mathrm{Hg}$ decay cascades are applied to measurements of nuclear quadrupole interactions in materials.
\end{abstract}

Key words: Nuclear Techniques; Hyperfine Fields; Semiconductors; Superconductors.

\section{Introduction}

The "hyperfine interaction techniques" which rely on properties of (mostly) excited nuclei were introduced in solid state physics research during the sixties. These techniques are complementary to Nuclear Quadrupole and Nuclear Magnetic Resonance (NQR, NMR) techniques that use stable isotopes with non-zero nuclear moments to probe hyperfine fields in materials. Mössbauer Effect (ME) [1], Perturbed Angular Correlations (PAC) [2], Nuclear Orientation (NO) [3] and $\beta$-Nuclear Magnetic Resonance ( $\beta$-NMR) [4] are examples of techniques that use excited states or unstable nuclei with non-zero magnetic and quadrupole moments. These radioactive techniques provide access to new probe elements, generally for impurity concentrations below the detection limit of the non-radioactive techniques.

The $\gamma-\gamma$ PAC technique has been extensively applied to materials science studies since the seventies. Its contribution to the microscopic characterisation of impurities and defects in bulk and surface materials is well demonstrated in $[2,5,6,7]$. For this technique excited nuclei that decay through $\gamma-\gamma$ cascades are necessary. The intermediate level should be an isomeric state with a half-life ranging from a few nanoseconds up to a few microseconds, and should have non-zero magnetic and/or quadrupole moments. One limitation of this technique that re- stricted its applications, is the limited number of radioactive probe elements with adequate isotopes. However, there are many cases in which the cascades involve highly converted low energy transitions and $\gamma-\gamma$ PAC can be efficiently replaced by $e^{-}-\gamma$ or even $e^{-}-e^{-}$PAC, thus increasing the number of probe elements available to new applications.

Finally it is worth mentioning that on-line production is the technical approach that best provides a large variety of radioactive isotopes. Several of such radioactive facilities exist or are being built around the world [8]. Among such, the best example is the ISOLDE/CERN (Isotope Separator On-Line/European Organisation for Nuclear Research) facility at Geneva [9], due to its high diversity, isotopic purity, and high yields of the radioactive beams. At ISOLDE the radioactive isotopes are produced by bombardment of different target materials by the $1 \mathrm{GeV}$ proton beam from the PS-Booster accelerator at CERN. Plasma sources, surface ion sources or highly element-selective laser ion sources are coupled to the targets and ionise the desired elements. Then applying a high voltage produces a $60 \mathrm{keV}$ beam, which is mass separated by high resolving power magnets.

In this paper we will briefly introduce the $e^{-}-\gamma$ PAC technique and the experimental setup at ISOLDE. Then, examples of ongoing studies using the highly converted isotopes ${ }^{73} \mathrm{As} /{ }^{73} \mathrm{Ge}\left(T_{1 / 2}=80 \mathrm{~d}\right),{ }^{127} \mathrm{Ba} /{ }^{127} \mathrm{Cs}\left(T_{1 / 2}=\right.$ 
$13 \mathrm{~min})$ and ${ }^{197 \mathrm{~m}} \mathrm{Hg} /{ }^{197} \mathrm{Hg}\left(T_{1 / 2}=124 \mathrm{~h}\right)$ will be presented and discussed.

\section{The $e^{-}-\gamma$ PAC Technique: An Overview}

The PAC technique has been extensively presented and discussed in many papers and textbooks $[2,6,10,11]$. We will only mention here a few relevant features that help to understand the differences and similarities between $\gamma-\gamma$ and $e^{-}-\gamma$ PAC.

Briefly, PAC relies on the fact that the detection of the first $\gamma$-ray $\left(\gamma_{1}\right)$ of the cascade defines a principal quantification axis, $k_{1}$, in the detector direction along which the $m$ states of the spin $I$ of the intermediate state are unequally populated (e.g., see [6]). In consequence, due to angular momentum conservation, the intensity distribution of the second $\gamma$-ray $\left(\gamma_{2}\right), W(\theta)$, will be anisotropic in space relative to $k_{1}$.

$$
W(\theta) \propto 1+\sum_{k=2,4, \ldots} A_{k}\left(\gamma_{1}\right) A_{k}\left(\gamma_{2}\right) P_{k}(\cos \theta),
$$

In (1) $A_{k}(\gamma)$ represents the anisotropy coefficients that, for each transition of the cascade, depend only on angu- lar momentum selection rules applied to the spins of the initial and final states and of the multipolarity of the $\gamma$ transitions [12]. $P_{k}(\cos \theta)$ are the Legendre polynomials that reflect the angular dependence of $W(\theta)$. Then, the coupling of the nuclear magnetic and quadrupole moments of the intermediate state with the materials magnetic field and electric field gradiant, respectively, will change the $m$ state population. In the case of a static interaction, the density of states will change periodically with time, inducing a time dependent modulation, $G_{k k}(t)$, of the $\gamma_{2}$ spatial distribution (Figure 1). Equation (2) represents $W(\theta, t)$ for the simple case when the local field is randomly oriented.

$$
W(\theta, t) \propto e^{-t / \tau}\left(1+\sum_{k=2,4, \ldots} A_{k}\left(\gamma_{1}\right) A_{k}\left(\gamma_{2}\right) P_{k}(\cos \theta) \cdot G_{k k}(t)\right) .
$$

This perturbation is observable superimposed onto the histogram measurement of the half-life of the intermediate state, and contains all information about the coupling between the nuclear moments and the hyperfine fields. The $\gamma_{1}-\gamma_{2}$ PAC maximum observable amplitude of the perturbation function is essentially determined by the products $A_{k}\left(\gamma_{1}\right) \cdot A_{k}\left(\gamma_{2}\right)$. The main observable effects

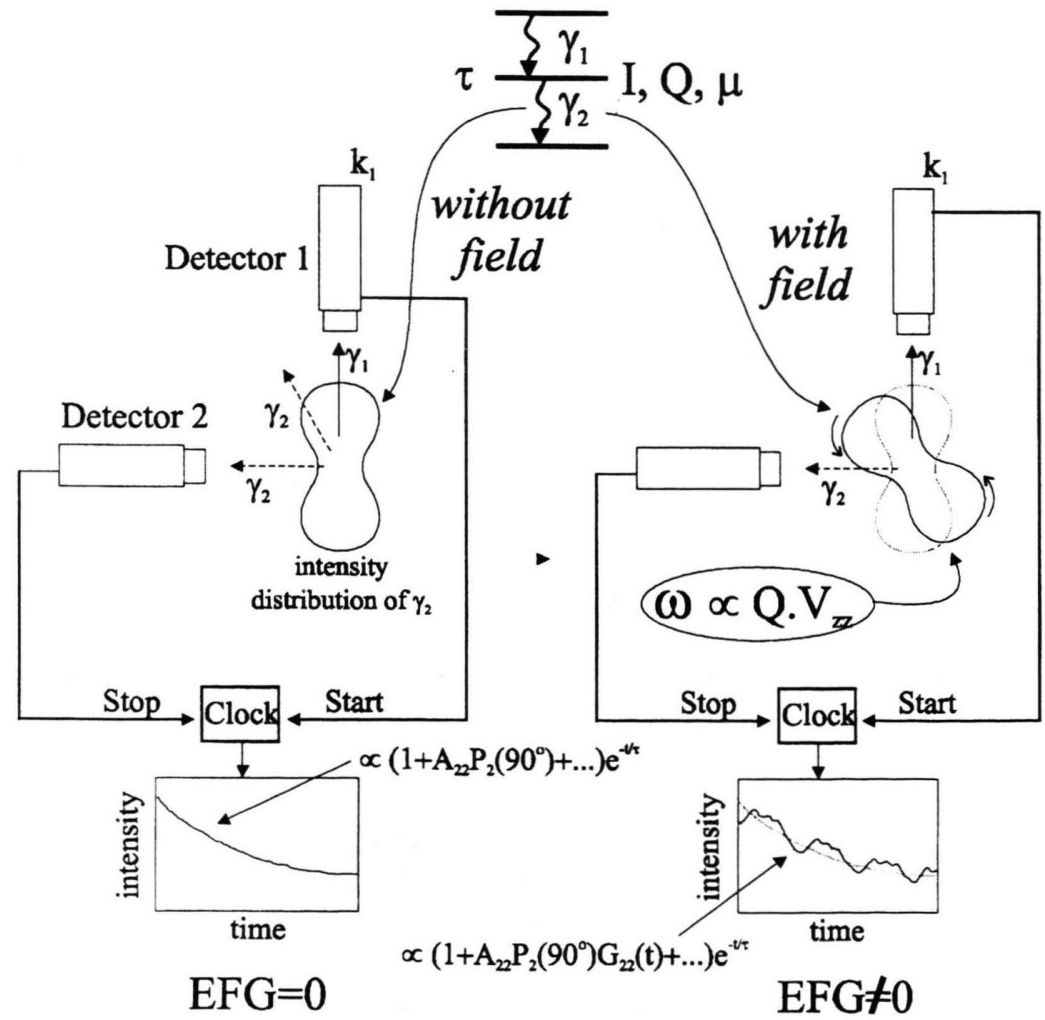

Fig. 1. Artistic representation of the PAC technique. The expressions are approximations valid for the cases when the external nuclear field is an electric field gradient (EFG) that is randomly oriented, like in a polycrystalline sample. $V_{Z Z}$ and $Q$ are defined in the text. 
Table 1. Characteristic parameters of most current PAC isotopes adequated for $e^{-}-\gamma$ PAC. The values of the conversion coefficients, $\alpha$, particle parameters, $b_{2}$, and anisotropy values, $b_{2} A_{22}$, are specific of the $\mathrm{K}$ or $\mathrm{L}$ atomic shells from where the electron is ejected.

\begin{tabular}{|c|c|c|c|c|c|c|c|c|}
\hline \multicolumn{2}{|c|}{ Parent iosotope } & \multicolumn{7}{|c|}{ PAC isotope } \\
\hline Element & $T_{1 / 2}$ & Element & $\begin{array}{c}\text { Cascade } \\
1^{\text {st }} \text { transition } 2^{\text {nd }} \text { transition } \\
e^{-}(\mathrm{keV}, \mathrm{M})-\gamma\left(\mathrm{keV}, \mathrm{M}^{\prime}\right)\end{array}$ & $\alpha$ & $b_{2}$ & $b_{2} A_{22}$ & $\begin{array}{l}T_{1 / 2} \\
(\mathrm{~ns})\end{array}$ & $r^{\pi}$ \\
\hline $\begin{array}{l}{ }^{73} \mathrm{As} \\
{ }_{111 \mathrm{~m}} \mathrm{Cd} \\
{ }^{119 m} \mathrm{Sn} \\
{ }^{127} \mathrm{Ba} \\
{ }_{1181} \mathrm{Hf} \\
{ }^{197 m} \mathrm{Hg} \\
{ }^{199 m} \mathrm{mg}\end{array}$ & $\begin{array}{l}80 \mathrm{~d} \\
49 \mathrm{~m} \\
293 \mathrm{~d} \\
13 \mathrm{~m} \\
42 \mathrm{~d} \\
24 \mathrm{~h} \\
43 \mathrm{~m}\end{array}$ & $\begin{array}{l}{ }^{73} \mathrm{Ge} \\
{ }^{111} \mathrm{Cd} \\
{ }^{119} \mathrm{Sn} \\
{ }^{127} \mathrm{Cs} \\
{ }^{181} \mathrm{Ta} \\
{ }^{197} \mathrm{Hg} \\
{ }^{199} \mathrm{Hg}\end{array}$ & $\begin{array}{c}\gamma(53, \mathrm{M} 2)-e_{\mathrm{L}}^{-}(13, \mathrm{E} 2) \\
e_{\mathrm{K}}^{-}(151, \mathrm{E} 3)-\gamma(245, \mathrm{E} 2) \\
e_{\mathrm{L}}^{-}(66, \mathrm{M} 4)-\gamma(24, \mathrm{M} 1) \\
\gamma(115, \mathrm{M} 1)-e_{\mathrm{L}}^{-}(66, \mathrm{E} 2) \\
e_{\mathrm{K}}^{-}(133, \mathrm{E} 2)-\gamma(482, \mathrm{E} 2+\mathrm{M} 1) \\
e_{\mathrm{L}}^{-}(165, \mathrm{M} 4)-\gamma(134, \mathrm{E} 2) \\
e_{\mathrm{K}}^{-}(374, \mathrm{M} 4)-\gamma(158, \mathrm{E} 2)\end{array}$ & $\begin{array}{c}780 \\
1.5 \\
2600 \\
8 \\
0.5 \\
300 \\
3.5\end{array}$ & $\begin{array}{l}+1.26 \\
+1.3 \\
+0.95 \\
+1.26 \\
+1.82 \\
+0.97 \\
+1.06\end{array}$ & $\begin{array}{l}+0.13 \\
+0.23 \\
-0.15 \\
-0.25 \\
-0.56 \\
+0.21 \\
+0.24\end{array}$ & $\begin{array}{c}2860(30) \\
85.0(7) \\
17.8(2) \\
24.9(2) \\
10.8(1) \\
8.10(8) \\
2.40(2)\end{array}$ & $\begin{array}{l}5 / 2^{+} \\
5 / 2^{+} \\
3 / 2^{+} \\
5 / 2^{(+)} \\
5 / 2^{+} \\
5 / 2^{-} \\
5 / 2^{-}\end{array}$ \\
\hline
\end{tabular}

when performing angular correlations with conversion electrons can be taken into account using new anisotropy coefficients, $A_{k}\left(e^{-}\right)$, which are simply calculated as the products $A_{k}\left(e_{x}^{-}\right)=b_{k}(\mathrm{E}, \mathrm{Z}, \mathrm{M}, \mathrm{X}) . A_{k}(\gamma)$ in the case of pure multipolar transitions. The particle parameters, $b_{k}(\mathrm{E}, \mathrm{Z}, \mathrm{M}, \mathrm{X})$, are strongly dependent on the energy of the nuclear transition $E$, on the atomic number of the element, $\mathbf{Z}$, on the multipolarity of the transition, $\mathbf{M}$, and on the atomic orbital from where the electron is ejected, $\mathrm{X}=\mathrm{K}, \mathrm{L}, \mathrm{M}, \ldots$. However, to calculate the $A_{k}\left(e_{x}^{-}\right)$coefficients is an easy task once most of the cascades are well characterised and the particle parameters have been tabled for most of all elements [12]. In Table 1 we show the relevant parameters of currently used isotopes for $e^{-}-\gamma$ PAC. It is particularly important to note that the particle parameter is in general greater than one, amplifying the observable anisotropy of the $\gamma-\gamma$ correlation, which can be advantageous even when the conversion coefficient is small [13].

The $e^{-}-\gamma$ PAC spectrometer consists of two magnetic lenses of the Siegbahn type $[14,15]$ for detection of conversion electrons, and two $\mathrm{BaF}_{2}$ scintillators for $\gamma$ detection, all arranged in one plane. As shown in Fig. 2, each lens is at relative $90^{\circ}$ with one $\gamma$ detector and $180^{\circ}$ with the other. In this way a classical four-detector PAC spectrometer is formed, with two start-detectors and two stop-detectors. The sample is situated inside a vacuum chamber, with the side to be implanted facing both magnetic lenses.

For one-line implantation and measurement, the ISOLDE ion beam enters the chamber through a narrow tube, $30 \mathrm{~cm}$ long and $1.2 \mathrm{~cm}$ wide, mounted in between the magnetic lenses. Albeit this narrow aperture, a beam transmission of $90 \%$ is achieved. The sample holder is mounted on a feed-through system that allows sample

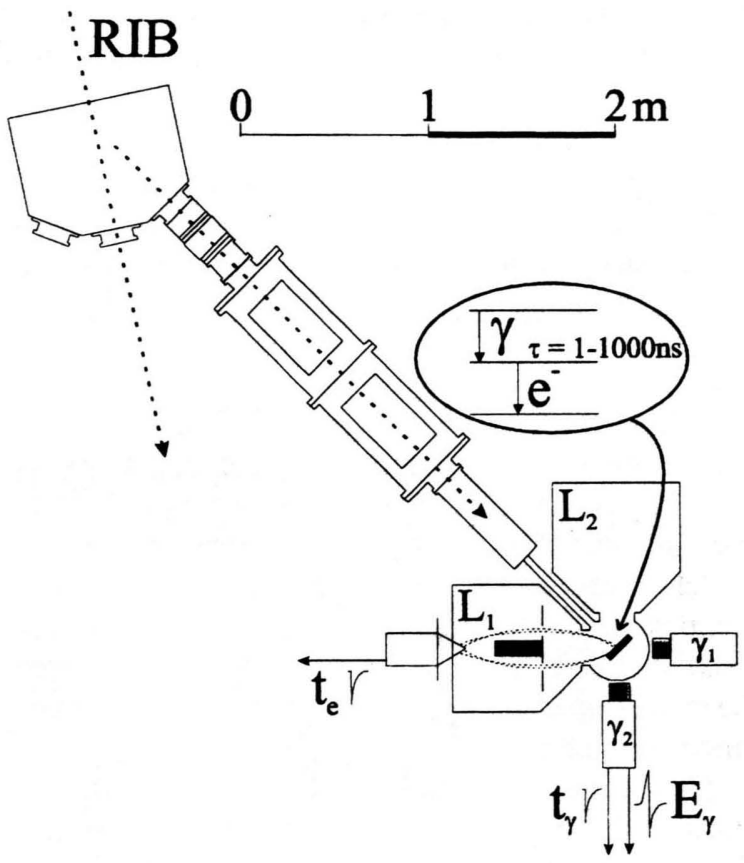

Fig. 2. General view of the $e^{-}-\gamma$ PAC spectrometer mounted on-line with the ISOLDE beam line. RIB denotes "Radioactive Ion Beams".

changing without breaking the vacuum in the chamber. Moreover, by having the sample holder directly connected to heating equipment, it is possible to implant and measure within a large temperature range up to $923 \mathrm{~K}$. Measurements can also be performed off-line, e.g., when complex annealing procedures are required. When performing $e^{-}-\gamma$ PAC experiments at low temperatures it is essential to avoid the condensation of residual gas at the sample's surface, since that will absorb and scatter the 
conversion electrons emitted by the shallow implanted radioactive nuclei. Absorption and scattering lead to decrease of electron intensity, to the electron energy spread and, most important, to the loss of the anisotropy of the angular correlation, in particular for low energy electrons. With the successful installation of a cryogenic system, which allows for cooling the samples down to $30 \mathrm{~K}$, low temperature $e^{-}-\gamma$ PAC experiments will soon become feasible [16]. Under typical working vacuum of $\sim 5 \times 10^{-7}$ mbar, the condensation of residual gas at the sample's surface was efficiently reduced. Therefore the experiments can run at $30 \mathrm{~K}$ during $48 \mathrm{~h}$ periods after which the sample's surface should be baked, to remove the condensed gas, by heating it up to RT.

A magnetic lens has specific advantages for PAC studies. Compared to the usual $\mathrm{NaI}$ or $\mathrm{BaF}_{2}$ scintillators used in $\gamma-\gamma$ PAC, the energy resolution of the electron detector is better, usually in the order of a few percent, and the conversion electrons from the right transition can be selected without admixtures from other ones. Since energy selection takes place before detection, the count rate in the detector is significantly reduced. In this way it is possible to use weak lines in the presence of other intense transitions, or to use stronger activities without overloading the detectors and subsequent electronic circuits. Electron detection in the magnetic lenses is achieved using plastic scintillators in order to optimize the time resolution. The energy resolution of the plastic scintillators is only important for low energy electrons $(E<15 \mathrm{keV})$, for which most of the signal falls within the photomultiplier's noise. To separate efficiently the signal for such low energy electrons a pre-acceleration system has been developed and successfully used in several measurements with the ${ }^{73} \mathrm{Ge}$ probe [17].

The currently used $\mathrm{BaF}_{2}$ scintillators are 2 " thick to ensure a good efficiency for a wide range of energies. Transistorised bases coupled to XP2020Q photomultipliers ensure a stable operation up to $200 \mathrm{kHz}$ for anode pulses with $\sim 1000 \mathrm{mV}$ amplitude. The time resolution is strongly dependent on the electron and gamma energies, being $1.0 \mathrm{~ns}$ (FWHM) for ${ }^{111 \mathrm{~m}} \mathrm{Cd},{ }^{197 \mathrm{~m}} \mathrm{Hg}$ and ${ }^{199 \mathrm{~m}} \mathrm{Hg}$ cascades, $2.5 \mathrm{~ns}$ for the ${ }^{127} \mathrm{Ba} /{ }^{127} \mathrm{Cs}$ cascade and $4.5 \mathrm{~ns}$ for the ${ }^{73} \mathrm{As} /{ }^{73} \mathrm{Ge}$ cascade.

The PAC spectrometer collects 4 time spectra from time coincidences between the conversion electron and the gamma radiation from the first and the second transitions. These are detected by one electron-gamma detector pairs at relative angles of $\theta=180^{\circ}$ or $\theta=90^{\circ}$, whose counting rates are denoted by $N_{j}\left(180^{\circ}, t\right)$ and $N_{i}\left(90^{\circ}, t\right)$, $j=i=1,2$ respectively. The experimental function $R(t)$, is constructed according to

$$
R(t)=2 \frac{\sqrt{\prod_{j}^{2} N_{j}\left(180^{\circ}, t\right)}-\sqrt{\prod_{i}^{2} N_{i}\left(90^{\circ}, t\right)}}{\sqrt{\prod_{j}^{2} N_{j}\left(180^{\circ}, t\right)}+2 \sqrt{\prod_{i}^{2} N_{i}\left(90^{\circ}, t\right)}} .
$$

This ratio eliminates the half-live exponential component, revealing the perturbation function that contains all the relevant information. For each angle $\theta$, the angular correlation functions, $W(\theta, t)$, are calculated numerically when the EFGs are oriented (in single-crystalline samples) or randomly distributed (in poly-crystalline samples), by taking into account the full Hamiltonian for the quadrupole hyperfine interaction $[2,10,18]$. The theoretical function, $R_{\mathrm{fit}}(t)$, whose parameters are fitted to the experimental $R(t)$ function, is defined by

$$
R_{\mathrm{fit}}(t)=2 \frac{W\left(180^{\circ}, t\right)-W\left(90^{\circ}, t\right)}{W\left(180^{\circ}, t\right)+2 W\left(90^{\circ}, t\right)} .
$$

For a cascade with an intermediate level with spin $I=5 / 2$, three frequencies are observable per EFG. From these frequencies the coupling constant of the interaction, $v_{\mathrm{Q}}=e Q V_{z z} / h$, and the asymmetry parameter $\eta=$ $\left(V_{x x}-V_{y y}\right) V_{z z}$ can be extracted. $V_{z z}$ is the principal component of the EFG tensor that is produced by the charge distribution outside the probe nucleus and $Q$ is the quadrupole moment of the intermediate excited state.

In the case of interactions with randomly distributed defects or with time dependent EFGs a distribution of frequencies is observed instead of a sharp frequency [19]. In many cases, however, even when the distributions are due to implantation defects, the shape of the distributions is not known. Then Lorentzian or Gaussian-like distributions, which are characterised by a mean value $\left\langle v_{\mathrm{Q}}\right\rangle$ and standard deviation $\sigma_{\mathrm{Q}}$, can be chosen to reproduce the attenuation of the $R(t)$ spectrum.

\section{Results}

\section{1. ${ }^{73} \mathrm{As} /{ }^{73} \mathrm{Ge}$ Probe}

A probe nucleus that is not an impurity in elemental semiconductors is a must for studies of defects and impurities in $\mathrm{Si}, \mathrm{Ge}$ and $\mathrm{Si}-\mathrm{Ge}$ alloys. The best candidate is the $53-13 \mathrm{keV}$ cascade in ${ }^{73} \mathrm{Ge}$ (Figure 3 ). The $13 \mathrm{keV}$ state is also a potential candidate for high resolution Mössbauer spectroscopy [20]. However, due to the extremely long half-life, $T_{1 / 2}=2.86 \mu \mathrm{s}$, the linewidth is very 


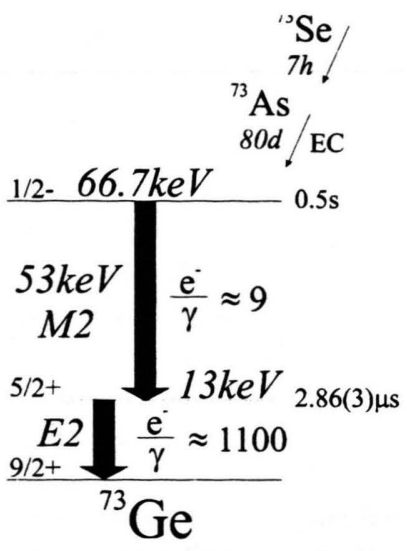

Fig. 3. Schematic representation of the ${ }^{73} \mathrm{Ge}$ cascade populated in the ${ }^{73}$ As decay.

small and it is difficult to find and characterise the resonance. The fact that this cascade is highly converted excludes the use of the $\gamma-\gamma$ PAC technique. Additional difficulties arise from the low energy of the Lelectrons from the $13 \mathrm{keV}$ transition $(12 \mathrm{keV})$, whose signals fall within the noise level of the photomultiplier electron detector. Recently, this problem was eliminated by pre-accelerating the electrons out of the noise level, thus allowing first successful experiments that characterised the nuclear magnetic and quadrupole moments of the ${ }^{73} \mathrm{Ge} 13 \mathrm{keV}$ state [17].

Figure 4 shows the experimental PAC functions, $R(t)$, obtained in the decay of ${ }^{73} \mathrm{As}$ for magnetic hyperfine interaction of ${ }^{73} \mathrm{Ge}$ in Ni foil (Fig. 4a) and quadrupole interaction of ${ }^{73} \mathrm{Ge}$ in a Sb single crystal (Figure $4 b$ ). The magnetic interaction in $\mathrm{Ni}$ foil was studied with $\gamma(53 \mathrm{keV})-e_{\mathrm{L}}^{-}(13 \mathrm{keV})$ coincidences, while the gamma absorption in the thick Sb sample obliged us to perform $e_{\mathrm{K}}^{-}(53 \mathrm{keV})-e_{\mathrm{L}}^{-}(13 \mathrm{keV})$ coincidences to measure the quadrupole interaction. Each measurement ran for about 30 days. From the measured ${ }^{73} \mathrm{GeNi}$ Larmor frequency, $\omega_{\mathrm{L}}=74.2(7) \mathrm{Mrad} \cdot \mathrm{s}^{-1}$, the ${ }^{73} \mathrm{GeSb}$ quadrupole frequency, $v_{\mathrm{Q}}=19.7$ (2) MHz, the known values of the hyperfine field for $\mathrm{Ge}$ in $\mathrm{Ni}$ and the $\mathrm{EFG}$ for $\mathrm{Ge}$ in $\mathrm{Sb}$, we obtained $|g|=0.430(12)$ and $|Q|=0.70(8)$ b for the $13 \mathrm{keV}$ state in ${ }^{73} \mathrm{Ge}[17]$. Since then this isotope has been applied to several studies in semiconductors [21,22].

A potential application of this isotope is to study the hydrogen passivation of shallow impurities in semicon-
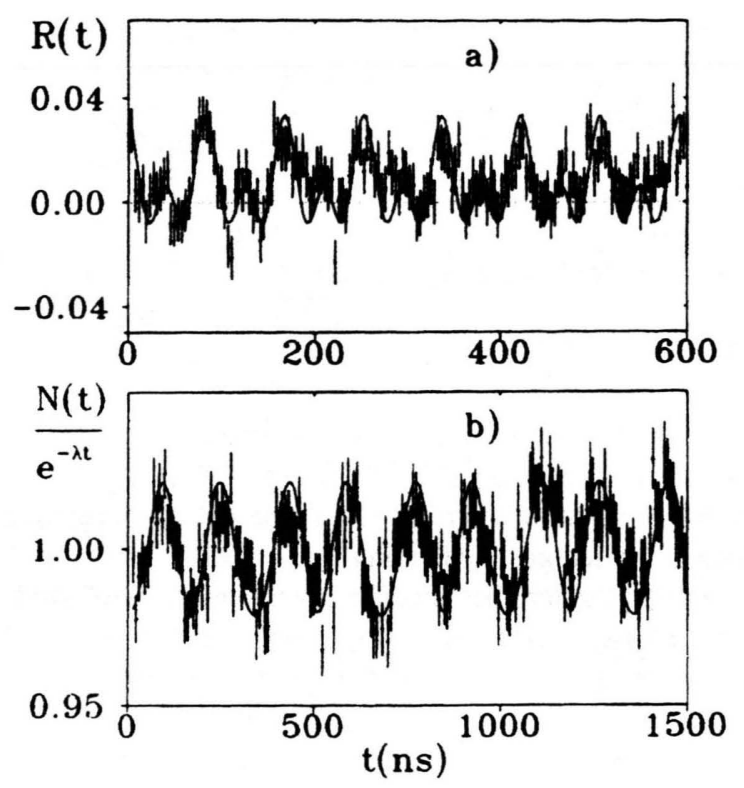

Fig. 4. (a) Anisotropy ratio, $R(t)$. for ${ }^{73} \mathrm{Ge}$ in Ni foil obtained with $\gamma(53 \mathrm{keV})-e_{\mathrm{L}}^{-}(13 \mathrm{keV})$ coincidences; (b) Perturbation function for ${ }^{73} \mathrm{Ge}$ in an Sb single crystal with $c$-axis on the detector plane at $45^{\circ}$ oriented in between the magnetic lenses obtained with $e_{\mathrm{K}}^{-}(53 \mathrm{keV})-e_{\mathrm{L}}^{-}(13 \mathrm{keV})$ coincidences.

ductors. While the passivation of shallow acceptors has been extensively studied, significantly less is known on the donor-hydrogen interaction [23]. Since the parent isotope ${ }^{73} \mathrm{As}$ is a donor in $\mathrm{Si}$ it is able to trap hydrogen. After the radioactive decay $\left(T_{1 / 2}=80 \mathrm{~d}\right)$ into the excited state $\left(I=1 / 2^{-}\right)$of the isovalent daughter isotope ${ }^{73} \mathrm{Ge}$ (Fig. 3) hydrogen is no more bound to the probe atom by Coulomb interaction. Thus the free hydrogen diffusion can be observed as a function of temperature within the time window defined by the nuclear half-life $\left(T_{1 / 2}=0.5 \mathrm{~s}\right)$ of the first excited state of ${ }^{73} \mathrm{Ge}$. First PAC experiments have been done on the interaction of hydrogen with ${ }^{73} \mathrm{As}$ implanted silicon at room temperature (RT) $[21]$.

Figure 5a shows two $R(t)$ spectra of a Si sample after implantation and subsequent annealing at 570 and $1220 \mathrm{~K}$. After annealing at $570 \mathrm{~K}$ a fraction $f_{\mathrm{S}}=62(8) \%$ of the ${ }^{73} \mathrm{Ge}$ probe atoms are located on lattice sites within a slightly perturbed environment, characterised by an EFG distribution centered at $\left\langle v_{\mathrm{QS}}\right\rangle=0 \mathrm{MHz}$ with a standard deviation $\sigma_{\mathrm{QS}}=3.4(3) \mathrm{MHz}$. The rest of the probe atoms $f_{\mathrm{D}}=38(8) \%$ are located in a heavily perturbed environment. With increasing annealing temperature the fraction $f_{\mathrm{D}}$ decreases while the fraction $f_{\mathrm{S}}$ increases and the standard deviation $\sigma_{\mathrm{QS}}$ of the corresponding EFG distribu- 

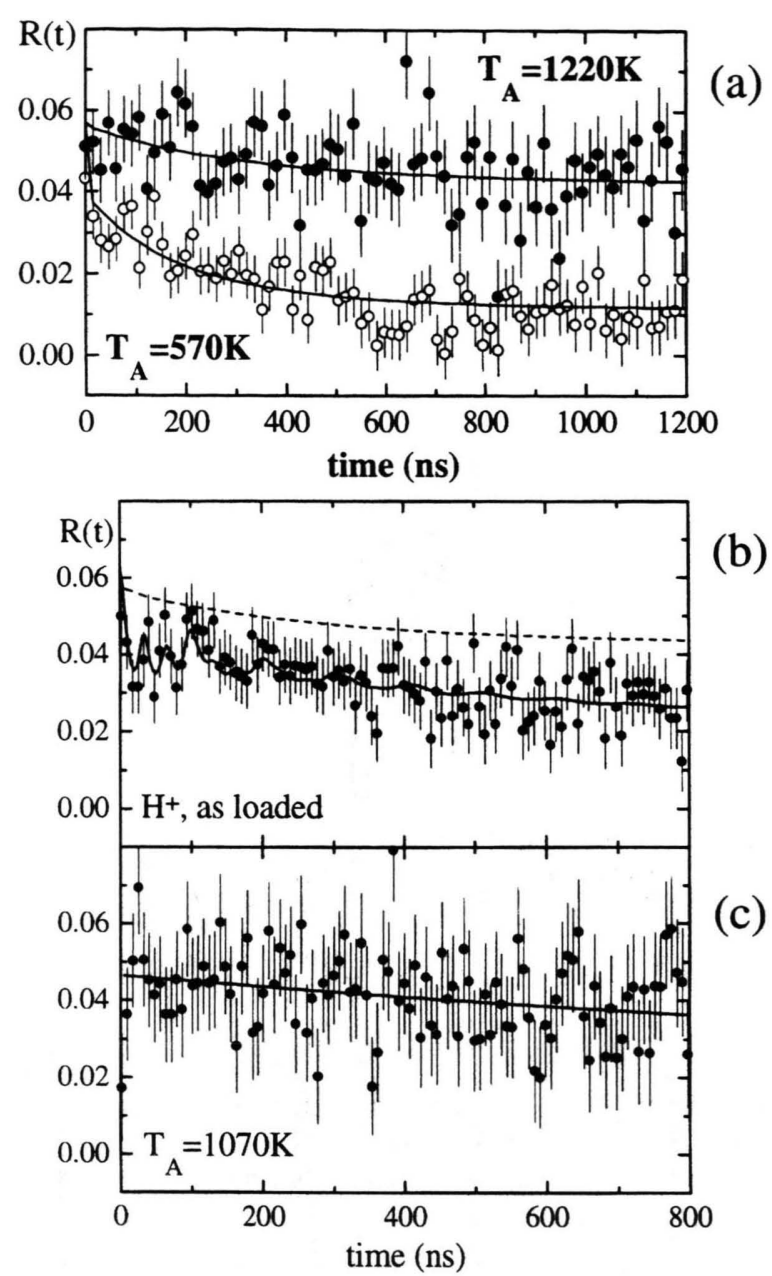

Fig. 5. (a) $R(t)$ PAC experimental function measured at room temperature, after implantation of ${ }^{73} \mathrm{As}$ and annealing at $570(5) \mathrm{K}$ and after annealing at $1220(20) \mathrm{K}$. (b) $R(t)$ spectra taken after hydrogen loading and (c) after annealing at $1070(5) \mathrm{K}$. The dashed line represents the $T_{A}$ at $1220 \mathrm{~K}$ annealed spectrum, before the hydrogen loading.

tion decreases. After annealing at $1220 \mathrm{~K}$ a fraction $f_{\mathrm{S}}=90(9) \%$ of the probe atoms interacts with randomly distributed defects leading to a weak EFG distribution characterised by $\left\langle v_{\mathrm{QS}}\right\rangle=0 \mathrm{MHz}$ and $\sigma_{\mathrm{QS}}=$ $0.16(2) \mathrm{MHz}$. This indicates the removal of the implantation damage for the majority of the probe nuclei which we assume to be located on substitutional lattice sites in agreement with Emission Channeling measurements [24]. After annealing, the samples have been implanted at $400 \mathrm{~K}$ with a dose of $5 \times 10^{15} \mathrm{at} / \mathrm{cm}^{2}$ of $\mathrm{H}^{+}$with $300 \mathrm{eV}$, below the threshold energy for the creation of Frenkel pairs in Si.
Figure 5 shows the PAC spectra measured at RT after $\mathrm{H}^{+}$loading (b) and after annealing at $1070 \mathrm{~K}(\mathrm{c})$. Immediately after $\mathrm{H}^{+}$loading a modulation of the $R(t)$ spectrum appears which was fitted considering two EFG distributions characterised by their average values $\left\langle v_{\mathrm{Q} 1}\right\rangle=65(2) \mathrm{MHz}$ and $\left\langle v_{\mathrm{Q} 2}\right\rangle=204(10) \mathrm{MHz}$ and the corresponding standard deviations $\sigma_{\mathrm{Q} 1}=4.6(6) \mathrm{MHz}$ and $\sigma_{\mathrm{Q} 2}=14.2(2) \mathrm{MHz}$, respectively. More than $50 \%$ of all probe atoms interact with these EFGs $\left(f_{1}=17(4) \%\right.$, $f_{2}=36(4) \%$ ). After annealing at $1070 \mathrm{~K}$ both fractions $f_{1}$ and $f_{2}$ vanish but without recovering the previous situation before hydrogen was loaded. In fact the fraction of the probe atoms which are located on almost unperturbed lattice sites, $f_{\mathrm{S}}=72(5) \%$ is smaller and the standard deviation $\sigma_{\mathrm{QS}}=0.28(1) \mathrm{MHz}$ is greater than the corresponding values measured before hydrogenation. The observed EFGs which give origin to the non-vanishing $\left\langle v_{\mathrm{Q} 1}\right\rangle$ and $\left\langle v_{\mathrm{Q} 2}\right\rangle$ frequency values must be due to ${ }^{73} \mathrm{As} / \mathrm{Ge}$ trapped hydrogen atoms or hydrogen correlated defects which are not yet mobile at RT. At RT the diffusion of a single $\mathrm{H}$ atom should be fast enough to leave the nearest neighbourhood of the ${ }^{73} \mathrm{Ge}$ atom, which is isovalent to $\mathrm{Si}$, within the first $0.5 \mathrm{~s}$ after the decay of ${ }^{73} \mathrm{As}$. Therefore we propose that the observed complexes are hydrogen related, either consisting of several $\mathrm{H}$ atoms or H-defect clusters, which are immobile at RT. Since the implanted $\mathrm{H}$ dose of $5 \times 10^{15} \mathrm{at} / \mathrm{cm}^{2}$ was rather high it might well be that, complexes consisting of more that one $\mathrm{H}$ atom or $\mathrm{H}$ and defects are formed. The high hydrogen dose can also be the reason why the situation previous to the hydrogen implantation was not recovered after annealing at $1070 \mathrm{~K}$. In fact it is well known that high concentrations of hydrogen can produce many stable defects such as hydrogen agglomerates in $\mathrm{Si}$.

The application of the electron-gamma PAC technique to the ${ }^{73} \mathrm{As} /{ }^{73} \mathrm{Ge}$ decay opens new possibilities on material studies with a semiconductor probe. Obviously the accurate measurement of electric field gradients and magnetic hyperfine fields, including their temperature dependence, would be a straightforward application. Also the study of semiconductors with this new technique, particularly defects and impurities in $\mathrm{Ge}$, would be very interesting. In particular, As is a n-type dopant in $\mathrm{Si}$ and Ge that enables the trapping of hydrogen. Then PAC measurements at temperatures below the onset of the hydrogen diffusion should allow the observation of the single, unbound hydrogen at the probe atom after the decay of ${ }^{73} \mathrm{As}$ into the isovalent impurity ${ }^{73} \mathrm{Ge}$. Thus it would be possible to directly observe the diffusion of the isolated hydrogen in $\mathrm{Si}$ and $\mathrm{Ge}$. 


\section{2. ${ }^{127} \mathrm{Ba} /{ }^{127} \mathrm{Cs}$ Probe}

An alkali probe element is desirable to study several problems in solid state research. As examples we mention the study of diffusion mechanisms that depend on the interaction of alkali impurities with implantation defects in ferromagnetic metals [25] and the probing of charge density shifts at the Ba site on High- $\mathrm{T}_{C}$ superconductors [26]. Recently, PAC measurements on the $66.0 \mathrm{keV}$ excited state of ${ }^{127} \mathrm{Cs}$ have been successfully performed, by using the $\gamma(115 \mathrm{keV})-e_{\mathrm{L}}^{-}(66 \mathrm{keV})$ cascade (Fig. 6) fed in the decay of the short lived ${ }^{127} \mathrm{Ba}$ [27]. Here we introduce the ${ }^{127} \mathrm{Ba} /{ }^{127} \mathrm{Cs}$ decay as a new $\mathrm{PAC}$ probe for hyperfine interaction studies.

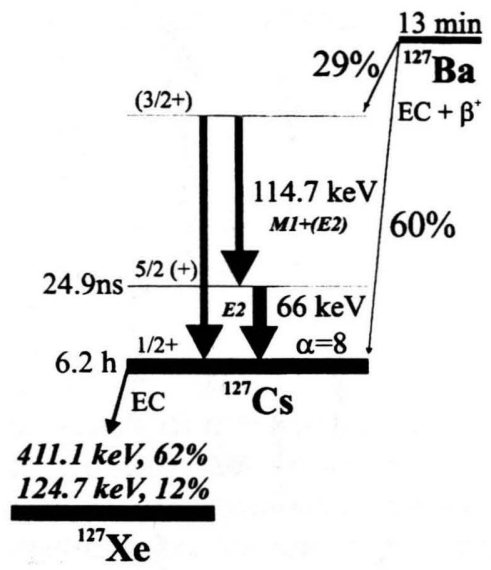

Fig. 6. Simplified decay schema of the ${ }^{127} \mathrm{Ba} /{ }^{127} \mathrm{Cs}$ decay. The two most intense gamma lines obtained from the ${ }^{127} \mathrm{Cs} /{ }^{127} \mathrm{Xe}$ decay are also indicated.

Figure 7 shows the half-life histogram of the $66.0 \mathrm{keV}$ state, which was obtained by performing time coincidences between the $114.7 \mathrm{keV} \gamma$-line and the $\mathrm{L}(66 \mathrm{keV})$ conversion electrons. From this histogram a precise value of the half-life of the $66.0 \mathrm{keV}$ state, $T_{1 / 2}=24.88(30) \mathrm{ns}$, was obtained. The quoted error includes the time calibration uncertainty of $1 \%$. The resolving time of the experimental setup was measured during the decay of ${ }^{127} \mathrm{Cs}$ to ${ }^{127} \mathrm{Xe}$. By letting the $\gamma$ and electron energy windows set as during the PAC experiments, $\beta^{+}$and conversion electrons, which are inelastically scattered in the sample, are detected in prompt coincidence with the ${ }^{127} \mathrm{Xe} 124.7 \mathrm{keV}$ $\gamma$-line. In this way a prompt spectrum with FWHM= 2.43(3) ns is obtained.

Figure 8 shows the experimental $R(t)$ functions measured during implantation of ${ }^{127} \mathrm{Ba}$ at $453 \mathrm{~K}$ in a Be hcp

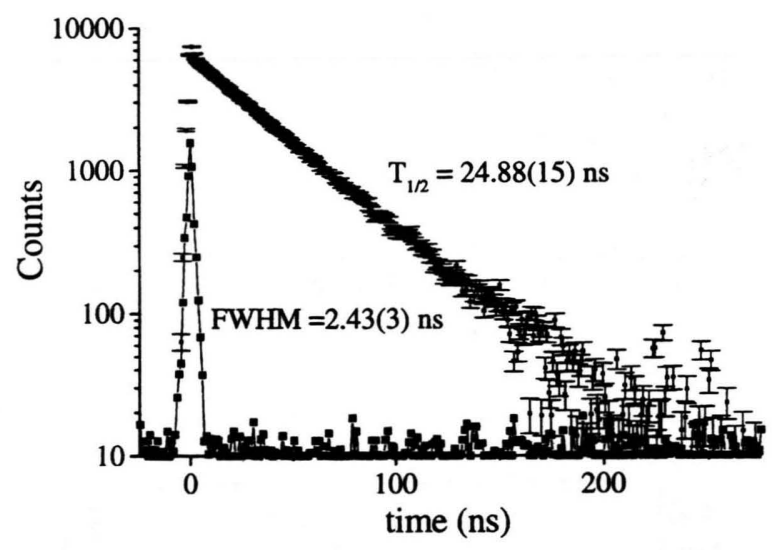

Fig. 7. Measurements of the half-life of the $66.0 \mathrm{keV}{ }^{127} \mathrm{Cs}$ state, and of the time resolution of the experimental setup.

single crystal (Fig. 8a) and during implantation at RT in a Ga sample (Figure 8b). About $f_{1}=47(9) \%$ of the ${ }^{127} \mathrm{Ba} /{ }^{127} \mathrm{Cs}$ nuclei occupy the same lattice site in the Be single crystal, which EFG is characterised by $\left|v_{\mathrm{Q} 1}\right|=$ 358.8(25) MHz and $\eta_{1}=0$, without defects in their neigh$\operatorname{bourhood}\left(\sigma_{\mathrm{Q} 1}=0\right)$. The rest of the Ba nuclei are randomly located or associated with defects on the Be lattice, whose mean EFG is characterised by $\left\langle v_{\mathrm{Q} 2}\right\rangle=v_{\mathrm{Q} 1}$, and $\sigma_{\mathrm{Q} 2}=1770(142) \mathrm{MHz}$. After RT implantation in the Ga sample (Fig. 8b), $100 \%$ of the ${ }^{127} \mathrm{Ba} /{ }^{127} \mathrm{Cs}$ nuclei are located in the same site of the orthorhombic lattice, whose EFG is characterised by $\left|v_{\mathrm{Q} 1}\right|=125.5(7) \mathrm{MHz}$ and $\eta_{1}=0.119(16)$. The $R(t)$ spectra measured in the non-cubic metallic Be and $\mathrm{Ga}$ hosts have clearly shown a characteristic set of three observable frequencies per EFG, thus proving that the spin of the $66.0 \mathrm{keV}$ state is $I=5 / 2$.

The nuclear quadrupole moment was estimated in two different ways. The first one is based on general systematics of EFGs, applied to $\mathrm{Cs}$ in $\mathrm{Be}$, from where an empirical value for $|Q|=0.60(1) \mathrm{b}$ is obtained [27]. The second calculation is based on the known value of the quadrupole interaction of ${ }^{80} \mathrm{Rb}$ in $\mathrm{Ga}, v_{\mathrm{Q}}=50.8(1) \mathrm{MHz}$ with $\eta=0.283$ (5), obtained with the Perturbed Angular Distribution technique [28]. The quadrupole moment of the $561 \mathrm{keV}$ state where the measurement is performed, has been determined as $\left|Q\left({ }^{80} \mathrm{Rb}, 561 \mathrm{keV}\right)\right|=0.51(5) \mathrm{b}$ [29]. Since $\mathrm{Rb}$ is isovalent to Cs, we assume that $V_{Z Z}(\mathrm{CsGa}) /$ $V_{Z Z}(\mathrm{RbGa})=\left(1-\gamma_{\infty}(\mathrm{Cs})\right) /\left(1-\gamma_{\infty}(\mathrm{Rb})\right)$, where $\gamma_{\infty}$ are the Sternheimer factors that account for the polarisation of the electronic core [30]. We thus obtain $\mid Q\left({ }^{127} \mathrm{Cs} \mid=\right.$ $0.58(12) \mathrm{b}$. The magnitudes of both values found for $Q$, which were obtained in two independent ways, are in excellent agreement. It is interesting to note that ${ }^{127} \mathrm{Cs}$ has 

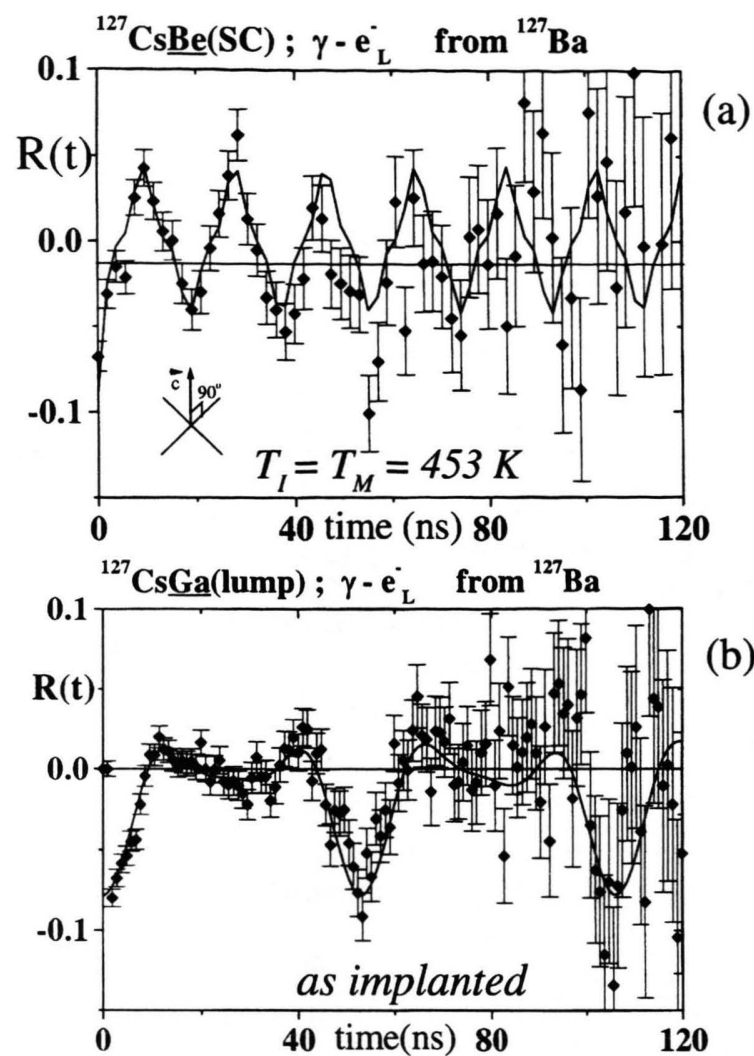

Fig. 8. (a) Experimental $R(t)$ function measured after implantation at $453 \mathrm{~K}$ of ${ }^{127} \mathrm{Ba}$ in a Be single crystal. The insert shows the orientation of the $c$-axis perpendicular to the detector plane. (b) Experimental $R(t)$ function measured after room temperature implantation of ${ }^{127} \mathrm{Ba}$ in $\mathrm{Ga}$ lump.

a quadrupole moment similar to the ground state of ${ }^{131} \mathrm{Cs}$ [31]. This observation may be explained by the fact that both nuclear states should have a similar single-particle configuration.

Some of the applications foreseen for this new PAC probe element involve investigations of high- $T_{\mathrm{C}}$ superconductors that contain $\mathrm{Ba} / \mathrm{Cs}$, studies of the interaction of point defects in metals with alkali-earth elements and also the study of amorphous to crystalline phase transitions in barium compounds.

\section{3. ${ }^{197 m} \mathrm{Hg} /{ }^{197} \mathrm{Hg}$ Probe}

The $e_{\mathrm{L}}^{-}(165 \mathrm{keV})-\gamma(134 \mathrm{keV}){ }^{197 \mathrm{~m}} \mathrm{Hg} /{ }^{197} \mathrm{Hg}$ cascade (Fig. 9) is well known for being an excellent case for $e^{-}-\gamma$ PAC due to the high conversion coefficient of the $165 \mathrm{keV}$ M4 transition (Table 1) and suitable $24 \mathrm{~h}$ half-

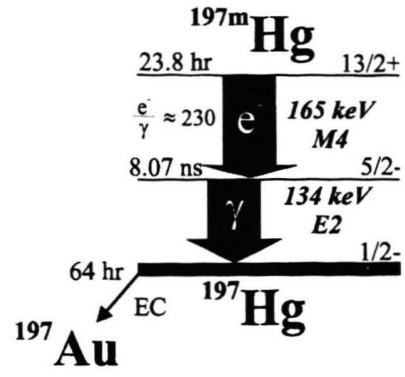

Fig. ${ }^{9}$. Schematic representation of the ${ }^{197} \mathrm{Hg}$ cascade in the ${ }^{197 \mathrm{~m}} \mathrm{Hg}$ decay.

life of the parent ${ }^{127 \mathrm{~m}} \mathrm{Hg}$ state [13]. At ISOLDE, in the past few years, the ${ }^{197 \mathrm{~m}} \mathrm{Hg}$ isotope was used to study hyperfine fields in metals [32] and semiconductors [33]. More recently both ${ }^{199 \mathrm{~m}} \mathrm{Hg}$ and ${ }^{197 \mathrm{~m}} \mathrm{Hg}$ isotopes are being applied to research in high- $T_{\mathrm{C}}$ superconductors of the $\mathrm{HgBa}_{2} \mathrm{Ca}_{\mathrm{n}-1} \mathrm{Cu}_{\mathrm{n}} \mathrm{O}_{2 \mathrm{n}+2+\delta}$ and $\mathrm{YBa}_{2} \mathrm{Cu}_{3} \mathrm{Q}_{6+\delta}$ (YBCO) families [34]. In the particular case of the YBCO material, the PAC experiments were motivated by previous works that reported that by doping with $\mathrm{Hg}$ the lattice stability is improved and the optimum critical temperature is raised by $10 \mathrm{~K}$ [35]. In [35] $\mathrm{Hg}$ was introduced into YBCO during sintering by changing the composition of the reactants. By replacing a few percent of $\mathrm{Ba}$ by $\mathrm{Hg}$ it was expected to dope the YBCO charge carrier block reservoirs. However, in those works the $\mathrm{Hg}$ site was not measured, and the presence of several crystalline phases, other than YBCO, cannot be excluded. Recently we combined the emission channeling (EC) and PAC techniques to show that $\mathrm{Hg}$ occupies a unique highly symmetric site in the YBCO lattice, already after implantation [36].

Figure 10a shows a PAC spectrum measured on a single-crystalline-like film at room temperature (RT) after ${ }^{197 \mathrm{~m}} \mathrm{Hg}$ implantation and subsequent annealing the sample at $723 \mathrm{~K}$ in flowing $\mathrm{O}_{2}$. The film was placed with its normal $(n)$ in the detector's plane, under an angle of $45^{\circ}$ to each electron detector. X-ray diffraction showed that the film was epitaxially grown, with the $c$-axis pointing towards $n$. The $R(t)$ spectrum was fitted assuming that all $\mathrm{Hg}$ probe nuclei interact with the same $\mathrm{EFG}_{1}$, characterized by a sharp $\left(\sigma_{\mathrm{Q} 1}=0\right)$ frequency centered at $\left\langle v_{\mathrm{Q} 1}\right\rangle=121.5 \pm 0.4 \mathrm{MHz}$, where $V_{z z}^{1}$ is aligned along $c$, and a small $\eta=0.19 \pm 0.02$. The value $\sigma_{\mathrm{Q} 1}=0$ reflects the fact that no point defects remain in the $\mathrm{Hg}$ atomic vicinity. Figure 10(b) and 10(c) show refined measurements of the EFG orientation where $R(t)$ spectra have been measured with $\boldsymbol{n}$ placed in the detector plane but now 


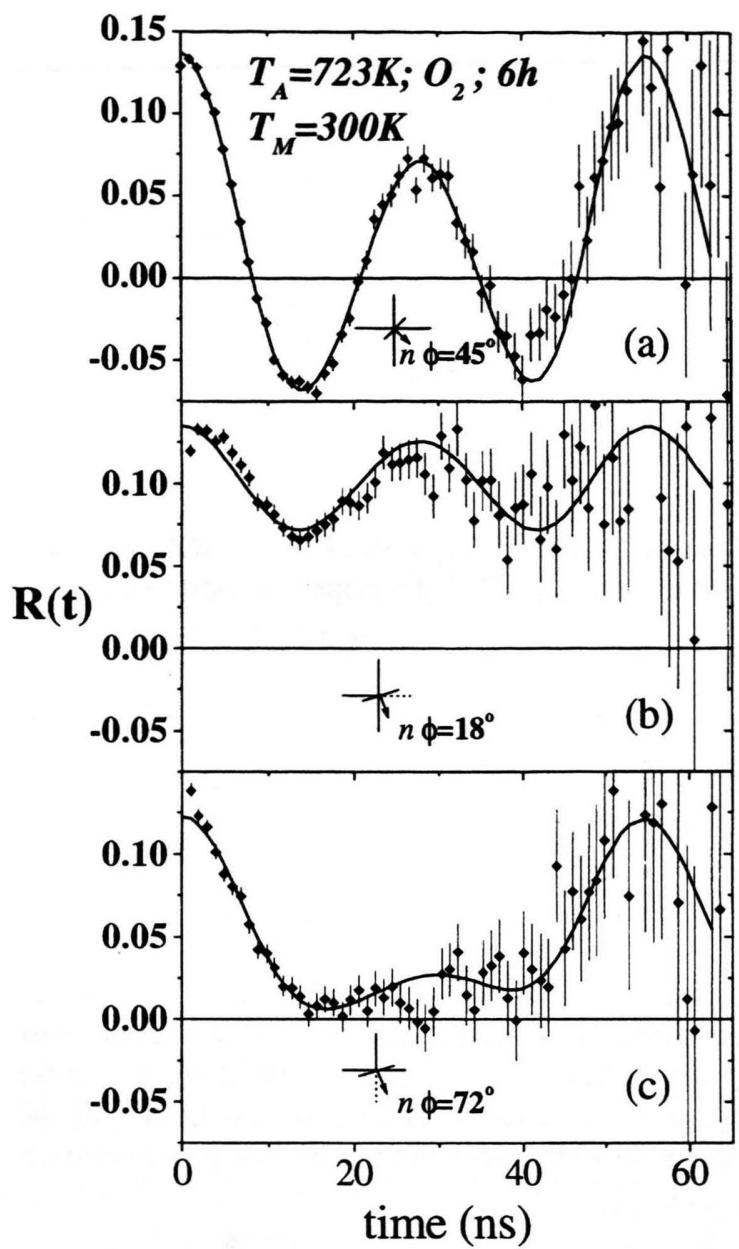

Fig. 10. PAC spectra measured on a single-crystalline-like film at room temperature implantation and annealing under flowing $\mathrm{O}_{2}$ at $723 \mathrm{~K}$. (a) $n$ is at $45^{\circ}$ with both electron detectors; (b) $n$ is at $18^{\circ}(\mathrm{b})$ and $72^{\circ}$ (c) with each electron detector, respectively.

under angles of $18^{\circ}$ and $72^{\circ}$ in respect to each electron detector directions, respectively. In these pictures the continuous lines are just simulations of the $R(t)$ spectra, assuming that $V_{z z}^{1}$ is fully aligned with $\boldsymbol{n} \| \mathrm{c}$, but now under an angle of $18^{\circ}$ or $72^{\circ}$ with respect to the electron detector. The agreement between the experimental data and the simulations is remarkable, thus confirming that $\mathrm{Hg}$ is located at unique sites of the YBCO lattice and surrounded by a charge distribution with the lattice symmetry. The fact that the magnitude of $\left|V_{z z}^{1}\right|$ is very close to $\left|V_{z z}\right|$ measured in ${ }^{199} \mathrm{~m} \mathrm{Hg}$ doped $\mathrm{HgO}$ strengthens the supposition that $\mathrm{Hg}$ in YBCO has two linear coordinat-

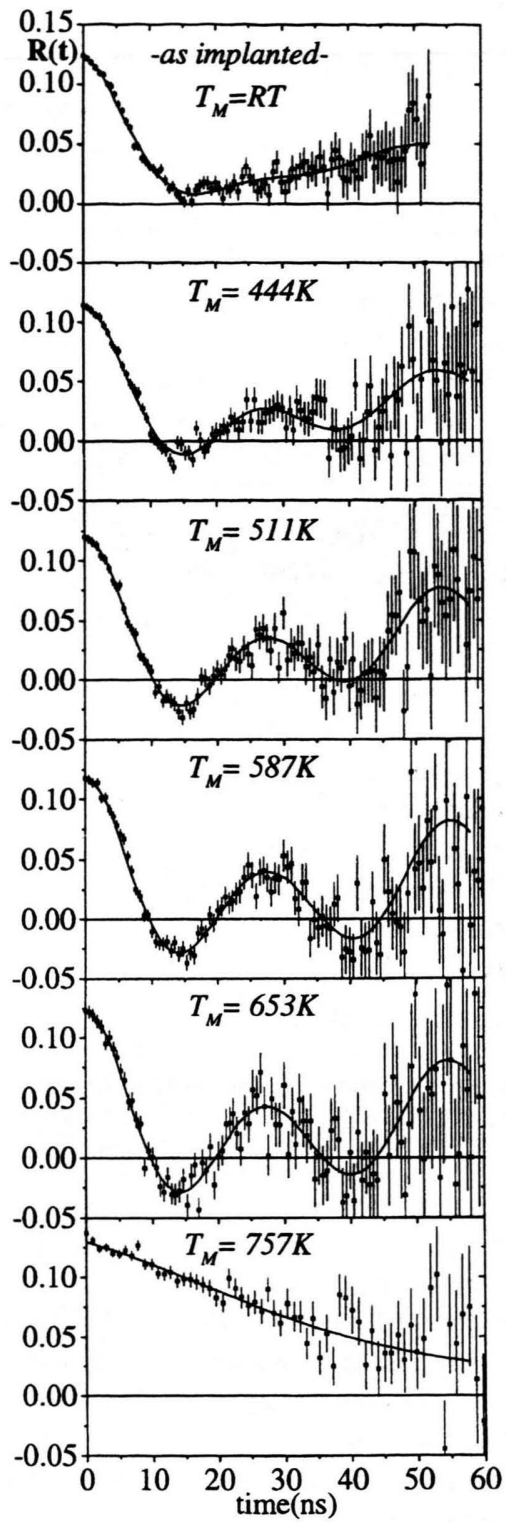

Fig. 11. PAC spectra measured after implantation and during annealing in vacuum up to $757 \mathrm{~K}$.

ed (apical) oxygen atoms as first neighbors, as it is the case for the $\mathrm{Cu}(1)$ lattice site. Complementary EC experiments and EC simulations, which have shown that $\mathrm{Hg}$ lies along the $\mathrm{Cu} c$-axis rows, further support this interpretation [37].

Figure 11 shows $R(t)$ spectra measured at several temperatures up to $757 \mathrm{~K}$. The vacuum was kept at 
$3 \times 10^{-6}$ mbar. All spectra are again fitted with only one main EFG interaction. Below $587 \mathrm{~K}$ that is characterised by one frequency triplet that reveals a slightly unsymmetrical but still unique $\mathrm{EFG}_{1}$. The strong attenuation of the as-implanted spectrum, which disappears at $511 \mathrm{~K}$, is due to $\mathrm{Hg}$ nuclei that interact with randomly distributed defects. Within the PAC range of sensitivity of a few nanometers around the $\mathrm{Hg}$ probe nuclei, the lattice recovers by annealing at $511 \mathrm{~K}$ and no point defects remain in the $\mathrm{Hg}$ neighborhood. For annealing temperatures above $511 \mathrm{~K} \mathrm{EFG}_{1}$ becomes axially symmetric $(\eta=0)$, thus revealing that the orthorhombic-to-tetragonal structural transition has occurred in our thin films between $511 \mathrm{~K}$ and $587 \mathrm{~K}$. In agreement with this, the $\chi_{\text {ac }}$ measurements show that due to the vacuum annealing, the superconductor compound was transformed into an antiferromagnetic insulator. Superconductivity was then reestrablished, and $T_{\mathrm{C}}$ recovered to the as-grown value, after $6 \mathrm{~h}$ annealing under $\mathrm{O}_{2}$ flow at $723 \mathrm{~K}$.

When annealing in vacuum above $653 \mathrm{~K} \mathrm{Hg}$ starts to diffuse out of the sample and the $R(t)$ spectra change irreversibly. Above $757 \mathrm{~K}$ only $\mathrm{EFG}_{2}$ is present with parameters $\left\langle v_{\mathrm{Q} 2}\right\rangle=23 \pm 3 \mathrm{MHz}$ and $\sigma_{\mathrm{Q} 2}=25 \pm 9 \mathrm{MHz}$. Moreover, this effect is irreversible when returning to lower annealing temperatures. The fact that $v_{\mathrm{Q} 2} \ll v_{\mathrm{Q} 1}$ is a hint that diffusion of the $\mathrm{Hg}$ ions must take place to lattice sites with higher symmetry, most likely not bound to oxygen anymore. However, recent experiments have shown that upon $6 \mathrm{~h}$ oxygen annealing at $723 \mathrm{~K}$ the initial PAC spectra is recovered to show again the $v_{\mathrm{Q} 1}$ frequency.

The $\mathrm{Hg}$ outdiffusion was studied by measuring as a function of annealing time the $\gamma$ count rate, $\mathrm{CR}_{\gamma}$ of the $134 \mathrm{keV}$ transition and the $\mathrm{PAC}$ coincidence rate, $\mathrm{CR}_{\mathrm{PAC}}$, at constant temperature. At a temperatur of $653 \mathrm{~K}$ (and highest $684 \mathrm{~K}, 757 \mathrm{~K}, 800 \mathrm{~K}, 888 \mathrm{~K}$ ) both $\mathrm{CR}_{\gamma}$ and $\mathrm{CR}_{\mathrm{PAC}}$ decrease faster than expected from the ${ }^{197 \mathrm{~m}} \mathrm{Hg}$ decay. When analysing the data, the count rates were corrected for the natural decrease due to the radioactive decay, and normalised to unity at the beginning of each measurement. The decrease of $\mathrm{CR}_{\gamma}$ and $\mathrm{CR}_{\mathrm{PAC}}$ with time was equal, thus indicating that $\mathrm{Hg}$ is diffusing out. If $\mathrm{Hg}$ would only diffuse within the film, then $\mathrm{CR}_{\mathrm{PAC}}$ would decrease faster than $\mathrm{CR}_{\gamma}$, due to higher absorption and scattering of the conversion electrons through the film.

Figure 12a shows the average $\left(I_{N}\right)$ of the $C_{\gamma}$ and $\mathrm{CR}_{\mathrm{PAC}}$ corrected normalised intensities. It is clearly seen that the rate of $\mathrm{Hg}$ loss increases with $T_{\mathrm{M}}$. $I_{\mathrm{N}}$ is proportional to the remaining ${ }^{197 \mathrm{~m}} \mathrm{Hg}$ nuclei into the film, thus it is proportional to the integral in depth of the $\mathrm{Hg}$ density distribution. The solid lines in Fig. 12a are fits as-

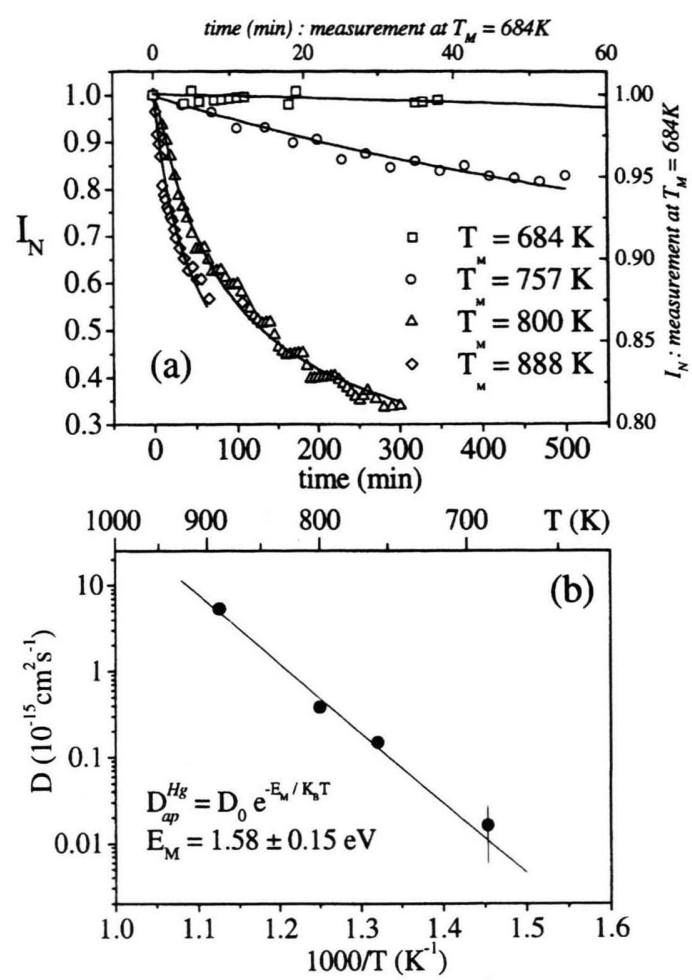

Fig. 12. (a) $I_{\mathrm{N}}$ plotted as a function of annealing time $\left(I_{\mathrm{N}}=\mathrm{av}\right.$ erage of $C R \gamma$ and $C_{\text {PAC }}$ count rates after half-life correction and normalisation, see text). At $684 \mathrm{~K}$ the diffusion is very slow, and during a short analysis only few points were taken. For the clearness of the picture, these points are plotted with different scales that are shown at the top and right axis. (b) Arrhenius plot of the apparent $\mathrm{Hg}$ diffusion coefficient. Solid lines are fits detailed in [28].

suming a simple one-dimension Gaussian-like diffusion distribution in a semi-infinite film without surface traps. The apparent diffusion coefficient $D_{a p}^{\mathrm{Hg}}\left(T_{\mathrm{M}}\right)$ obtained is plotted as a function of the reciprocal temperature in Figure $12 \mathrm{~b}$. The solid line is a fit with an Arrhenius law from which the migration energy for $\mathrm{Hg}$ in oxygen deficient YBCO lattice was found to be $E_{\mathrm{M}}=1.58 \pm 0.15 \mathrm{eV}$. Finally, the abundance of oxygen seems to delay the $\mathrm{Hg}$ diffusion, since after annealing at $723 \mathrm{~K}$ under $\mathrm{O}_{2}$ flow only a small amount of $\mathrm{Hg}$ was lost and the value of $\mathrm{EFG}_{1}$ did not change.

\section{Conclusions}

To date, the potential of the $e^{-}-\gamma$ PAC technique is far from extensively explored. Two main reasons contribute 
to this fact. The first one is the need for an increased and more regular access to facilities like ISOLDE which provide a range of different isotopes. The second reason is the need of an appropriate $e^{-}-\gamma$ PAC setup, where the use of electron spectrometers is mandatory since it is necessary to shield the electron detector from $\gamma$-rays while having a good resolution in energy and time.

To illustrate today's potential of the $e^{-}-\gamma$ PAC technique we have reviewed some of the technical features and focused on examples of ongoing studies that use highly converted isotopes. Two extreme cases were presented of new applications of the long-lived ${ }^{73} \mathrm{As} /{ }^{73} \mathrm{Ge}$ decay to studies on hydrogen passivation of $n$-type dopants in $\mathrm{Si}$, and the first PAC measurements of the EFG of $\mathrm{Cs}$ in $\mathrm{Be}$ and $\mathrm{Ga}$, made with the short lived ${ }^{127} \mathrm{Ba} /{ }^{127} \mathrm{Cs}$ decay. Finally we presented recent applications of the ${ }^{197 \mathrm{~m}} \mathrm{Hg} /{ }^{197} \mathrm{Hg}$ decay to studies on $\mathrm{Hg}$ implanted YBCO

[1] D. L. Williamson, L. Nielsen, G. Weyer, R. Sielemann, and G. Langouche, in Hyperfine Interactions of Defects in Semiconductors, ed. G. Langouche, Elsevier, Amsterdam 1992, p. 1.

[2] Th. Wichert, N. Achziger, H. Metzner, and R. Sielemann, Perturbed Angular Correlation, in Hyperfine Interactions of Defects in Semiconducturs, ed. G. Langouche, Elsevier, Amsterdam 1992, p. 1.

[3] N. J. Stone, in Low-temperature Nuclear Orientation, eds. N. J. Stone and H. Postma, North-Holland, Amsterdam 1986, p. 641.

[4] J. Christiansen, ed., Hyperfine Interactions of Radioactive Nuclei, Springer-Verlag Berlin 1983, p. 1.

[5] J. G. Correia and the ISOLDE Collaboration, Nucl. Instrum Meth. B136-138, 736 (1998).

[6] T. Wichert and E. Recknagel, in "Microscopic Methods in Metals”, ed. U. Gonser, Springer-Verlag, Berlin 1986, p. 317.

[7] H. Granzer, H. H. Bertschat, H. Haas, W.-D. Zeitz, J. Lohmüller, and G. Schatz, Phys. Rev. Lett. 77, 4261 (1996).

[8] E.g., in Proc. $13^{\text {th }}$ Int. Conf. on Electromagnetic Isotope Separators (EMIS-13) (Bad Durkheim, 1996) Nucl. Instrum. Meth. B126 (1997).

[9] E. Kugler, D. Fiander, B. Jonson, H. Haas, A. Przewloka, H. L. Ravn, D. J. Simon, K. Zimmer and the ISOLDE Collaboration, Nucl. Instrum. Method. B70 (1992) 41; B. Jonson, H. L. Ravn, and G. Walter, Nucl. Phys. News 3, 5 (1993).

[10] R. M. Steffen and K. Adler, in "The Electromagnetic Interaction in Nuclear Spectroscopy", ed. W. D. Hamilton, North Holland, Amsterdam 1975, p. 505.

[11] T. Butz, Hyp. Int. 52189 (1989).

[12] R. S. Hager and E. C. Seltzer, Nuclear Data A4, 397 (1968).

[13] E. N. Kaufmann, K. Krien, J. C. Soares, and K. Freitag, Hyp. Int. 1, 485 (1976).

[14] P. Kleinheinz, L. Samuelson, R. Vukanovic, and K. Siegbahn, Nucl. Instrum. Meth. 32, 1 (1965).

[15] J. G. Marques, J. G. Correia, A. A. Melo, M. F. da Silva, J. C. Soares, and the ISOLDE Collaboration, Nucl. Instrum. Meth. B99, 645 (1995). high- $T_{C}$ superconductor. These experiments, in particular, will benefit in the near future from the recent development of a cryogenic station for cooling down samples to be measured with the $e^{-}-\gamma$ PAC technique. Meanwhile, experiments are being prepared where the potential new $e^{-}-\gamma$ PAC isotopes ${ }^{83 \mathrm{~m}} \mathrm{Kr} /{ }^{83} \mathrm{Kr}, T_{1 / 2}=1.83 \mathrm{~h}$, $e_{\mathrm{L}}^{-}(32 \mathrm{keV}, \mathrm{E} 3)-\gamma(9 \mathrm{keV}, \mathrm{M} 1)$, and ${ }^{80 \mathrm{~m}} \mathrm{Br} /{ }^{80} \mathrm{Br}$, $T_{1 / 2}=4.4 \mathrm{~h}, e_{\mathrm{L}}^{-}(49 \mathrm{keV}, \mathrm{M} 3)-\gamma(37 \mathrm{keV}, \mathrm{E} 1)$ will be studied.

\section{Acknowledgements}

This work was partially funded by FCT, Portugal, through projects CERN/P/FIS/1024/98 and PBICT/C/ CTM/1891/95, and grants under the PRAXIS XXI Program (J.P.A., A.R.R.) R. Catherall is further acknowledged for proof reading.

[16] F. Espírito-Santo, J. G. Correia, A. A. Melo, J. P. Araújo, J. G. Marques, and J. C. Soares, to be published.

[17] J. G. Correia, H. Haas, J. G. Marques, A. A. Melo, J. C. Soares, and the ISOLDE Collaboration, Hyp. Int. 80, 1321 (1993).

[18] N. P. Barradas, M. Rots, A. A. Melo, and J. C. Soares, Phys. Rev. B47, 8763 (1993).

[19] M. Deicher, Hyp. Int. 79, 681 (1993).

[20] L. Pfeiffer, T. Kovacs, G. K. Celler, J. M. Gibson, and M. E. Lines, Phys. Rev. B27, 4018 (1983).

[21] J. G. Correia, J. G. Marques, D. Forkel-Wirth, A. Burchard, R. Magerle, M. Deicher, and the ISOLDE Collaboration, in Shallow-Level Centers in Semiconductors, eds. C. A. J. Ammerlaan and B. Pajot, World Scientific, Singapore 1997, p. 363.

[22] J. G. Correia, J. G. Marques, E. Alves, D. Forkel-Wirth, S. G. Jahn, M. Restle, M. Dalmer, H. Hofsäss, K. Bharuth-Ram, and the ISOLDE Collaboration, Nucl. Instrum. Meth. B127/128, 723 (1997).

[23] J. I. Pankove, N. M. Johnson (eds.) Hydrogen in Semiconductors, Semiconductors and Semimetals, vol. 34, Academic Press, New York 1991.

[24] S. Jahn, private communication (1996).

[25] M. Lindroos, H. Haas, J. de Wachter, H. Pattyn, and G. Langouche, Nucl. Instrum. Meth. B64, 256 (1992).

[26] R. Gatt, J. S. Olsen, L. Gerward, I. Bryntse, A. Kareiva, I. Panas, and L. G. Johansson, Phys. Rev. B57, 13922 (1998).

[27] J. G. Correia, J. G. Marques, J. C. Soares, A. A. Melo, $\mathrm{H}$. Haas, and the ISOLDE Collaboration, Nucl. Instrum. Meth. B152, 357 (1999).

[28] M. Menningen, H. Grawe, H. Haas, W.-D. Zeitz, and R. Keitel, in Ann. Rep. Hahn-Meitner Institut, Berlin 1979, p. 80.

[29] Ch. Stenzel, PhD Thesis, Freie Universität Berlin, 1986.

[30] F. D. Feiock and W. R. Johnson, Phys. Rev. 187, 39 (1969).

[31] P. Raghavan, Atomic Data and Nucl. Data Tables 42, 189 (1989).

[32] J. G. Marques, J. G. Correia, A. A. Melo, J. C. Soares, E. Alves, M. F. da Silva and the ISOLDE Collaboration. J. Appl. Phys. 76, 6906, (1994); E. Alves, J. G. Correia, J. G. Marques, A. A. Melo, M. F. da Silva, J. C. Soares, H. Haas, and the ISOLDE Collaboration, CERN, Nucl. Instr. Meth. B85, 457 (1994). 
[33] J. G. Marques, J. G. Correia, A. A. Melo, J. C. Soares, M. F. da Silva, M. D. Serrano, E. Diéguez and the ISOLDE Collaboration, Hyp. Int. C1, 408 (1996); J. G. Correia, J. G. Marques, J. C. Soares, E. Alves, M. F. da Silva, K. Freitag, R. Vianden, and the ISOLDECollaboration, Nucl. Instrum. Meth. B120, 144 (1996); E. Alves, M. F. da Silva, J. G. Marques, J. G. Correia, J. C. Soares, and K. Freitag, Nucl. Instrum. Meth. B120, 248 (1996).

[34] J. G. Correia et al., Studies of High-T ${ }_{C}$ Superconductors Doped with Radioactive Isotopes, CERN/ISC 96-30, ISC/P86, IS360 (1996)

[35] A. K. Chakraborty, K. Bose, G. Som, and B. K. Chaudhuri, J. Mater. Sci.: Mater. Electr. 5, 22 (1994).
[36] J. P. Araújo, J. G. Correia, U. Wahl, J. G. Marques, E. Alves, V. S. Amaral, A. A. Lourenço, V. Galindo, T. von Papen, J. P. Senateur, F. Weiss, A. Vantomme, G. Langouche, A. A. Melo, M. F. da Silva, J. C. Soares, J. B. Sousa, and the ISOLDE Collaboration, Nucl. Instrum. Meth. B148, 807 (1999); B147, 244 (1998); V. S. Amaral, J. G. Correia, A. A. Lourenço, J. G. Marques, J. A. Mendes, M. A. Baptista, J. P. Araújo, J. M. Moreira, J. B. Sousa, E. Alves, M. F. da Silva, J. C. Soares, and the ISOLDE Collaboration, J. Magnetism Magn. Mat. 177-181, 511 (1997).

[37] J. P. Araújo et al., to be published. 